co-authorship of this book, together with Kenneth Owen - journalist and editorial consultant to the Alvey directorate - is entirely in character in its detailed frankness about the problems and failings as well as the achievements of the Alvey programme. So also was his decision, which was novel at the time in Whitehall, to employ independent evaluators, charged with feeding back their assessments periodically throughout the programme.

The book is highly informative on the manouevrings within the information technology community that brought an ideologically ill-disposed government to the point of contributing $£ 200$ million of taxpayers' money to the programme. Analysts interested in the social construction of technology or in the operation of policy networks will find much of value here, as will readers with more general interests in how governments can be moved. The same richness of detail, sense of excitement and bluntness in assess- ments characterizes the discussions of how the programme was structured and administered, its development and achievements, and the failure of the Bide proposals.

If I have a criticism, it is that the use of quotations to capture the recollections and judgements of participants is overdone. It leads to repetition and, at times, unclear focus. The journalist's bias towards the provocative quotation sometimes wins out over the reader's desire to know whether, for example, a citation was typical or not of the people consulted. A tougher final editing would have been worthwhile. But this book does not claim to be the last word on Alvey. Its aim - to provide a personal memoir and to convey the flavour of the programme - is amply fulfilled, and later writers on Alvey will find it an invaluable source.

Philip Gummett is in the Department of Government, University of Manchester, Oxford Road, Manchester M13 9PL, UK.

\section{An atmosphere of thought}

\author{
Priscilla C. Grew
}

Science and Russian Culture in an Age of Revolutions. By Kendall E. Bailes. Indiana University Press: 1990. Pp. 238. $\$ 29.50$.

THE authors of a book on global change, History of the Earth's Atmosphere (Springer-Verlag, 1987), concluded: "controlling the chemical composition of the atmosphere . . . will be a great step towards the formation of the noosphere; and this will in turn realize the idea of the founder of biosphere science, V. I. Vernadsky". The authors, M. I. Budyko, A. B. Ronov and A. L. Yanshin, did not find it necessary to explain what "noosphere" means, nor who V. I. Vernadsky is. Many readers west of Berlin, however, will experience some hesitation in defining the word "noosphere", and few, unless they frequent the New Age bookstores, will recall ever having read anything written by the Ukrainian geochemist V. I. Vernadsky (1863-1945). At present there is only one paperback by Vernadsky in print in the United States, a translation of The Biosphere (written in 1926), published by the Synergetic Press in Oracle, Arizona.

The year 1988 was the 125th anniversary of Vernadsky's birth. For the occasion, the vice-president of the USSR Academy of Sciences wrote an article stating that Vernadsky "stands on a par" with Aristotle and Avicenna. Scientific conferences in Vernadsky's honour were held in Moscow, Leningrad, Kiev of primary sources, the book clearly documents Vernadsky's scientific achievements, such as his founding of the discipline of biogeochemistry and his promotion of biosphere science. Both these fields are increasingly critical for understanding global change.

Bailes also puts into context the noosphere business. Vernadsky, himself an historian of science, was careful to give credit to the mathematician Edouard Le Roy for originating the term "noosphere". Vernadsky's later development of the concept diverged from Teilhard de Chardin's mystical noosphere of a collective global consciousness, like an "envelope of thought". Vernadsky foresaw that inadvertent human interference in global biogeochemistry would gradually be succeeded by intentional human shaping of global change. He called this transition the evolution from the biosphere to the noosphere. For Vernadsky, the noosphere emerges as humans assume an ever greater role in managing, rather than "unconsciously" inducing global change. In Vernadsky parlance, our plan to diminish the hole in the ozone layer is a clear symptom of the emergence of the noosphere.

For Bailes, the central jewel of Vernadsky's legacy was his life-long "assertion of the primary value of freedom of thought for science and for human creativity" (p. 197). The archival record reveals that Vernadsky steadfastly sustained this assertion through revolution and war, arrest, censorship, and the disappearance and murder of students and friends. Bailes shows that Vernadsky advocated representative government and federalism, abhorred violence and courageously defended colleagues from political repression.

Does Vernadsky rank with Aristotle? Probably not, but perhaps the parallel to Avicenna (ibn Sina of Bukhara) is not so far-fetched. Both had catholic interests in science and philosophy, and it did take two centuries for ibn Sina to get his name and work translated into the Latin world of the West. A posthumous paper published in American Scientist in 1945, "The Biosphere and the Noosphere", is Vernadsky's only journal article in English. His striking portrait is the frontispiece. Like a chiaroscuro "St Jerome in the Study", Vernadsky, with long silver hair, white beard and downcast eyes, rests his bowed head on his clenched fist. Beneath the photograph are a few typewritten lines in Russian, cut from a letter to a friend. "I look forward very optimistically", he writes. He doesn't appear optimistic in the picture - but icons never smile.

Priscilla C. Grew is at the Minnesota Geological Sunvey, University of Minnesota, 2642 University Avenue, St Paul, Minnesota 55413, USA

\section{Environmental paperbacks}

- Now available in Bantam paperback is James Lovelock's The Ages of Gaia: A Biography of our Living Earth. For review see Nature 336, 270; 1988 . Price is $\$ 10.95$.

- The third edition of The Human Impact on the Natural Environment, by Andrew Goudie, was recently issued by Blackwell. Price is $£ 10.95$. (A hardback edition is available at £30.)

- Published on 5 July by Penguin, A Green Manifesto for the 1990 s by Penny Kemp and Derek Wall explains Green party policy in Britain - not only its environmental programme but also medical, defence and social issues. Price is $£ 4.99$. 